\title{
The aridity index governs the variation of vegetation characteristics in alpine grassland, Northern Tibet Plateau
}

\author{
Biying Liu ${ }^{1,2}$, Jian Sun ${ }^{\text {Corresp., } 2,3}$, Miao Liu ${ }^{2}$, Tao Zeng ${ }^{\text {Corresp., } 1}$, Juntao Zhu ${ }^{2}$ \\ ${ }^{1}$ College of Earth Sciences, Chengdu University of Technology, Chengdu, China \\ 2 Synthesis Research Centre of Chinese Ecosystem Research Network, Key Laboratory of Ecosystem Network Observation and Modelling, Institute of \\ Geographic Sciences and Natural Resources Research, Chinese Academy of Sciences, Beijing, China \\ ${ }^{3}$ State Key Laboratory of Urban and Regional Ecology, Research Center for Eco-environmental Sciences, Chinese Academy of Sciences, Beijing, China \\ Corresponding Authors: Jian Sun, Tao Zeng \\ Email address: sunjian@igsnrr.ac.cn, zengtao@cdut.cn
}

The vegetation dynamic (e.g., community productivity) is an important index used to evaluate the ecosystem function of grassland ecosystem. However, the critical factors that affect vegetation biomass are disputed continuously, and most of the debates focus on mean annual precipitation (MAP) or temperature (MAT). This article integrated these two factors, used the aridity index (Al) to describe the dynamics of MAP and MAT, and tested the hypothesis that vegetation traits are influenced primarily by the Al. We sampled 275 plots at 55 sites (five plots at each site, including alpine steppe and meadow) across an alpine grassland of the northern Tibet Plateau, used correlation analysis and redundancy analysis (RDA) to explore which key factors determine the biomass dynamic, and explained the mechanism by which they affect the vegetation biomass in different vegetation types via structural equation modelling (SEM). The results supported our hypothesis, in all of the environmental factors collected, the Al made the greatest contribution to biomass variations in RDA, and the correlation between the Al and biomass was the largest $(R=0.85, p \square 0.05)$. The final SEM also validated our hypothesis that the $\mathrm{Al}$ explained $79.3 \%$ and $84.4 \%$ of the biomass variations in the alpine steppe and the meadow, respectively. Furthermore, we found that the soils with higher carbon to nitrogen ratio and soil total nitrogen had larger biomass, whereas soil organic carbon had a negative effect on biomass in alpine steppe; however, opposite effects of soil factors on biomass were observed in an alpine meadow. The findings demonstrated that the Al was the most critical factor affecting biomass in the alpine grasslands, and different reaction mechanisms of biomass response to the Al existed in the alpine steppe and alpine meadow. 


\section{The aridity index governs the variation of vegetation characteristics}

\section{2 in alpine grassland, Northern Tibet Plateau}

3 Running head: Aridity regulates vegetation and soil

4 Biying Liu ${ }^{1,2}$, Jian Sun ${ }^{2,3 *}$, Miao Liu ${ }^{2}$, Tao Zeng ${ }^{1 *}$, Juntao Zhu²

$5 \quad{ }^{1}$ College of Earth Sciences, Chengdu University of Technology, Chengdu 610059, China;

6 25ynthesis Research Centre of Chinese Ecosystem Research Network, Key Laboratory of

7 Ecosystem Network Observation and Modelling, Institute of Geographic Sciences and Natural

8 Resources Research, Chinese Academy of Sciences, Beijing 100101, China

$9 \quad{ }^{3}$ State Key Laboratory of Urban and Regional Ecology, Research Center for Eco-environmental

10 Sciences, Chinese Academy of Sciences, Beijing 100085, China

B.Y.L.: 1by362428@163.com

M.L.:miaoliuerdos@163.com

J.T.Z.: zhujt@igsnrr.ac.cn

* Corresponding to: J.S.: sunjian@igsnrr.ac.cn; zengtao@cdut.cn

Tel.: +8618301068172

Address: Institute of Geographic Sciences and Natural Resources Research, Chinese Academy of

17 Sciences (CAS),11A, Datun Road, Chaoyang District, Beijing, 100101, China;

The number of words in the Abstract: 284

19 The number of words in main body of the paper: 2933

20 The number of references: 57

21 The number of Tables: 2 
22 The number of Figures: 6

23 The number of Supplementary materials: 1

25 ABSTRACT

26 The vegetation dynamic (e.g., community productivity) is an important index used to evaluate the ecosystem function of grassland ecosystem. However, the critical factors that affect vegetation biomass are disputed continuously, and most of the debates focus on mean annual precipitation (MAP) or temperature (MAT). This article integrated these two factors, used the aridity index (AI) to describe the dynamics of MAP and MAT, and tested the hypothesis that vegetation traits are influenced primarily by the AI. We sampled 275 plots at 55 sites (five plots at each site, including alpine steppe and meadow) across an alpine grassland of the northern Tibet Plateau, used correlation analysis and redundancy analysis (RDA) to explore which key factors determine the biomass dynamic, and explained the mechanism by which they affect the vegetation biomass in different vegetation types via structural equation modelling (SEM). The results supported our hypothesis, in all of the environmental factors collected, the AI made the greatest contribution to biomass variations in RDA, and the correlation between the AI and biomass was the largest $(\mathrm{R}=0.85, p<0.05)$. The final SEM also validated our hypothesis that the AI explained $79.3 \%$ and $84.4 \%$ of the biomass variations in the alpine steppe and the meadow, respectively. Furthermore, we found that the soils with higher carbon to nitrogen ratio and soil total nitrogen had larger biomass, whereas soil organic carbon had a negative effect on biomass in alpine steppe; however, 42 opposite effects of soil factors on biomass were observed in an alpine meadow. The findings 
43 demonstrated that the AI was the most critical factor affecting biomass in the alpine grasslands,

44 and different reaction mechanisms of biomass response to the AI existed in the alpine steppe and

45 alpine meadow.

\section{1. Introduction}

48 Grasslands are distributed widely in China and cover a total area of 4 million $\mathrm{km}^{2}$ (Sun et al. 2017).

49 As one of the most widespread vegetation types and an important component of the terrestrial

50 ecosystem (Li et al. 2016), grasslands occupy approximately 1.5 million $\mathrm{km}^{2}$ of the Tibetan

51 Plateau. Additionally, alpine grasslands (alpine steppe and meadow) dominate the natural

52 vegetation of the Tibetan Plateau and cover more than $60 \%$ of its area (Yang et al. 2009), and

53 alpine grassland plays an essential role in maintaining the ecosystem functions of the Tibetan

54 Plateau. However, due to the harsh climate of the Tibetan Plateau, the environmental factors under

55 the equilibrium conditions of the fragile surface system are usually in the critical threshold state

56 (Sun et al. 2019). Small fluctuations of climate change will also generate strong responses in the

57 ecosystem (Zhang et al. 2017) and lead to changes in the pattern, process and function of the

58 plateau grassland ecosystems; the manifestations of this including grassland degradation and

59 disappearance (Li et al. 2013; Yu et al. 2012). Consequently, the response mechanism of alpine

60 grasslands to soil properties, climate and other environmental factors is a new scientific problem

61 facing the research on environmental change of the Tibetan Plateau.

63 Biotic and abiotic factors constitute the fundamental forces that drive the quantity, distribution, 
64 structure, and diversity of vegetation communities. Numerous studies have investigated the effects

65 of precipitation, temperature, different land use types, and human disturbance on soil properties, biodiversity, and biomass in grassland ecosystems (Redmann et al. 1993; Sala \& Parton 1988; Sun et al. 2013a). They found that increased variability in precipitation had a strong effect on some arid land ecological processes (Thomey et al. 2015). Similarly, precipitation influenced aboveground biomass (BIO) and primary productivity strongly in most alpine grasslands (Hu et al. 2010; Huxman et al. 2004; O'Connor et al. 2001; Yang et al. 2009). Adler \& Levine (2007) hold that with increased mean annual precipitation (MAP) across a broad geographic gradient the mean plant species richness increased significantly. Additionally, temperature is another a critical factor, and some simulated warming experiments in alpine grasslands have shown that warming was associated with a decreased trend in aboveground net primary productivity and plant diversity (Cantarel et al. 2013; White et al. 2014); meanwhile, a negative correlation was observed between $\mathrm{BIO}$ and temperature when annual precipitation was held constant at about $50 \mathrm{~mm}$ (Epstein et al. 1996; Sala \& Parton 1988). It is important to note that responses of grassland to climate change also varied if soil properties are different (Noymeir 1973), for example, by increasing soil temperature reduced total plant community coverage in the peak growing peak season (Wang et al. 2015). Further, soil nitrogen also influenced species richness in a wide range of temperate grasslands (Critchley et al. 2010). Previous studies have indicated that plant-soil interactions were vital mechanisms in a grassland ecosystem (Orwin et al. 2010). Nevertheless, it is still controversial whether precipitation or temperature is the primary limiting environmental factor for vegetative traits (Sun et al. 2016; Sun et al. 2013a; Sun \& Qin 2016a; Wu et al. 2013). A limited 
85

86

87

number of studies has combined water and heat availability to address the contribution of climatic factors on vegetation characteristics. This study integrated these environmental variables, using the aridity index (AI) to describe the dynamics of precipitation and temperature. This study also proposed the hypothesis that the vegetation traits are influenced primarily by the AI. Because of the significant differences in precipitation and temperature between different vegetation types, we divided the research objects into steppe and meadow, then compared the contributions of the critical environmental variables to vegetation biomass, and explained the mechanism of environmental variables affecting biomass in these two vegetation types respectively.

\section{Materials \& methods}

\subsection{Study area}

The study was conducted on the alpine grassland in the northern Tibet Plateau $\left(80.38^{\circ}-92.01^{\circ} \mathrm{E}\right.$, $31.22^{\circ}-32.51^{\circ} \mathrm{N}$, average altitude of $\sim 4,600 \mathrm{~m}$ ) of southwestern China (Fig. 1). The typical continental plateau climate is characterized by low temperature and limited precipitation, with a short, cool summer and long, cold winter. The annual precipitation ranges from 79.91 to 465.27 $\mathrm{mm}$, and the mean annual temperature is $1.35^{\circ}$. Alpine grassland is one of the main ecosystems in the Tibetan Plateau, where the vegetation is alpine meadow (dominated by Kobresia spp. and Poa spp.) and alpine steppe (dominated by Stipa purpurea) (Sun et al. 2009; Zeng et al. 2015). Alpine meadow has a sub-frigid and semi-arid high-plateau monsoon climate, and alpine steppe has a frigid and high-plateau dry climate. Alpine meadow soil and alpine steppe soil are very compact and loosely structured, respectively (Zeng et al. 2018). 


\subsection{Survey design and sampling}

108

109

110

111

112

113

114

115

116

117

118

119

120

121

122

123

124

125

126

7

Plant BIO were collected from 55 sites (30 sites in alpine steppe and 25 sites in alpine meadow) along a transect at spatial intervals of $50 \mathrm{~km}$ in August 2012 (Fig. 1, Table 1). Five plots (replicates) of $1 \mathrm{~m} \times 1 \mathrm{~m}$ were randomly assigned to each sampling site $\left(5 \mathrm{~m}^{2}\right.$ area $)$. Plant BIO in these quadrats was harvested by a clipping method flush with the ground. All species information, including the vegetation coverage within each quadrat, was identified by a field guide (Cai et al. 1989), and the number of species in each quadrat was recorded to estimate diversity (Whittaker 1972). After the data were aggregated, all of the plant samples were de-enzymed at $85^{\circ} \mathrm{C}$ for $30 \mathrm{~min}$ and oven-dried at $65^{\circ} \mathrm{C}$ until a constant weight was achieved. Thereafter, the samples were weighed on an electronic scale (accurate to one one-hundredth of a gram).

8 Soil from the 0-30 cm layer was also sampled in the plots, and soil samples were stored in a refrigerator at $4^{\circ} \mathrm{C}$ until measuring chemical properties. We collected five soil cores using a $5 \mathrm{~cm}$ diameter soil auger and mixed them in situ into one composite sample. The soil organic carbon (SOC) and soil total nitrogen (STN) concentrations were determined using a vario MACRO cube elemental analyser (Ganjurjav et al. 2016). The mean annual temperature (MAT) and MAP were the mean values of temperature and precipitation in 2012 obtained from the Worldclim database (URL: http://www.worldclim.org/), and the outliers of the meteorological data acquired has been modified or removed. The database mentioned includes information on current global climate based on data collected from 1950 to 2000 and interpolated to a resolution grid of 2.5 arc min 
$127\left(\sim 5 \mathrm{~km}^{2}\right.$ grid cells at the equator, and smaller cells elsewhere) using information on latitude,

128 longitude, and elevation (Hijmans et al. 2005). The AI was calculated using the MAT and MAP

129 data according to Martonne's formula (de Martonne 1926).

130

$$
A I=\frac{P}{T+10}
$$

where $\mathrm{P}$ is $\mathrm{MAP}(\mathrm{mm})$ and $\mathrm{T}$ is $\operatorname{MAT}\left({ }^{\circ} \mathrm{C}\right)$.

\subsection{Data analysis}

134 The data package required in this study includes the target variable of BIO (BIO), and biotic factors 135 [coverage (COV), and species richness (SR)] and abiotic factors [(MAP, MAT, the AI, STN, SOC, and the soil carbon to nitrogen ratio $(\mathrm{C}: \mathrm{N})$ ] were selected to explore the response of $\mathrm{BIO}$ to these environment factors. Table 1 shows the specific information of the database.

First, we conducted a Pearson's correlation analysis (Corrplot package) using R software 2.11.1

(Team 2016) to screen out the variables that can reflect biomass changes. Second, the redundancy

analysis is a linear canonical ordination method that is related closely to the potential explanatory

et al. 2017). Thus, R (Vegan) was employed to explore the relationships between plant biomass

and the related variables that were filtered out and identify the key factor influencing BIO. To 
149 To demonstrate the reliability of our conclusions, we only used the AI and remaining independent

150 variables collected to explore the mechanism of biomass variation. The structural equation

151 modelling (SEM) approach was adopted to explain the mechanism by which the key factors affect

152 BIO, both directly and indirectly, in alpine steppe and meadow. SEM is a common multivariate

153 technique that has been used in recent studies to evaluate explicitly the causal relations among

154 multiple interacting variables (Sun et al. 2017). SEM differs from other modeling approaches as it tests both the direct and indirect effects on pre-assumed causal relationships (Fan et al. 2016). The standard estimate results express the influence on the BIO using a path coefficient generated by Amos software (17.0.2, Amos Development Corporation, Crawfordville, FL, USA).

3. Results

3.1. The relationships between environmental factors and aboveground biomass across alpine grasslands

According to Fig. 2, BIO was significantly correlated with four environmental variables at the $95 \%$ confidence interval level, including MAT $(\mathrm{R}=-0.76 ; p<0.05)$, MAP $(\mathrm{R}=0.76 ; p<0.05), \mathrm{C}: \mathrm{N}$ $(\mathrm{R}=-0.52 ; p<0.05)$, and the $\mathrm{AI}(\mathrm{R}=0.85 ; p<0.05)$ in alpine grasslands. In addition, these environmental factors above were also closely related to each other, example for AI, it was significantly correlated with MAP $(\mathrm{R}=-0.74 ; p<0.05)$ and MAT $(\mathrm{R}=0.97 ; p<0.05)$.

\subsection{Relative importance of the environmental factors}


169 The results showed that the interactions among MAP, MAT, C: N, and the AI were the main drivers 170 of the response variable (Fig. 3), explaining $79.82 \%$ of the variation in BIO. Specifically, the AI 171 had the greatest influence, explaining $72.16 \%$ of the BIO; followed by MAP, which explained $17258.34 \%$; and MAT and C: N, which explained 57.34\% and 26.25\% of the BIO, respectively.

3.3. The differences of aboveground biomass and the AI in the different grassland types

The $\mathrm{BIO}$ and the $\mathrm{AI}$ exhibited large differences between alpine steppe and meadow (Fig. 4 and

Table 1). The BIO ranged from 1.14 to $101.65 \mathrm{~g} \mathrm{~m}^{-2}$ in steppe, with a mean of $32.4 \mathrm{~g} \mathrm{~m}^{-2}$, and 3.18 significantly higher than that of steppe ( $p<0.01$, Fig. 4B). The AI between steppe and meadow was also entirely different $(p<0.05$, Fig. 4A). As shown in Table 1 , the AI of alpine meadow

largely was greater than 43.79 , whereas it was less than 27.22 in alpine steppe. The regression

analysis demonstrated that the BIO was exponential increasing with the AI values in both alpine steppe $\left(\mathrm{R}^{2}=0.75 ; p<0.001\right.$; Fig. 5) and meadow $\left(\mathrm{R}^{2}=0.77 ; p<0.001\right.$; Fig. 5). Notably, the vegetation in the alpine steppe and meadow exhibited different response rates to the AI. For BIO, with the same increase of AI, larger increases would be found in steppe than that in meadow, and when the AI value is around 26 , the BIO of the two tend to be equal.

3.4. Using structural equation modelling to explore the variations in aboveground biomass of alpine meadow and steppe The SEM results explained $84.1 \%$ (Fig. 6A) and $87.7 \%$ (Fig. 6B) of the variation in the BIO in 
190

191

192

193

194

195

196

197

198

199

200

201

202

203

204

205

206

207

208

209

210

alpine steppe and meadow, respectively. Table 2 shows a summary of the direct, indirect, and total effects of the variables. Clearly, in steppe and meadow, all independent variables included environmental factors (SOC, STN, C: N, and the AI) and biotic factors (coverage and species richness), both of which affected the dynamic change of $\mathrm{BIO}$, and all of the variables above are regulated directly or indirectly by the AI. As the SEM model results show (Table 2, Figs. 6), we also verified that the $\mathrm{AI}$ is the most critical factor affecting the variation in BIO. Furthermore, the weights contributed up to $79.3 \%$ (path coefficient $=0.793$ ) of the variation in BIO in the alpine steppe (Fig. 6A) and $84.4 \%$ (path coefficient $=0.844$ ) to the variation in BIO in alpine meadow (Fig. 6B).

In addition, the SEM showed that $\mathrm{C}$ : $\mathrm{N}$ and STN had positive effects while SOC had negative effects on BIO in alpine steppe, with path coefficients of $0.331,0.078$, and -0.091 , respectively (Fig. 6A). However, in alpine meadow, we observed the opposite effect, as C: N and STN had negative effects on BIO while SOC had positive effects. Their path coefficients were -0.303 , 0.161 , and 0.111 , respectively (Fig. 6B).

\section{Discussion}

Our results demonstrated that the AI was the primary limiting environmental factor for vegetation traits (Figs. 2, 3, and 5), and this finding supported our hypothesis. As we know, precipitation and temperature are key factors that affect the vegetation dynamic, and the aboveground biomass/vegetation index increased or decreased significantly depending on the more or less 
precipitation (Sun et al. 2013b; Sun \& Qin 2016b; Sun et al. 2016) and temperature (Sun et al.

212 2013a; Sun et al. 2016) in alpine grassland. Although the contributions of MAP and MAT to BIO

213 were all higher than $57 \%$ in our experiments, the AI had the greatest contribution $(72.16 \%)$ on

$214 \mathrm{BIO}$ (Fig. 3). As to identifying the complex network of causal relationships in ecosystems by SEM

215 (Sun et al. 2017), the direct effects of the AI on plant growth and photosynthesis cannot be ignored

216 (Chimner et al. 2010; Shi et al. 2014; Sun et al. 2013a). Different levels of the AI would lead to

217 significant differences in plant photosynthetic rate (Liu \& Chen 1990), and a lower AI level could

218 reduce the stomatal opening of the leaves; as a result, the $\mathrm{CO}_{2}$ supply was blocked, reducing

219 photosynthesis (Zhang et al. 2011). However, at this time, plant leaves can stabilize the function

220 of the photosynthetic mechanism by reducing the synergistic effects of light capture, heat

dissipation, and enzyme activity regulation to achieve the accumulation of dry matter (Flexas \&

Medrano 2002). When the AI was at a higher level, plant leaves can coordinate the relationship

between carbon assimilation and water consumption for transpiration through stomatal

conductance regulation (Paoletti et al. 1998), thus maintaining a high photosynthetic rate and water

use efficiency and promoting plant growth (Chengjiang \& Al 2002). As a result, if AI at a lower

level, the increases in $\mathrm{BIO}$ is minimum; and once $\mathrm{AI}$ is larger than a certain point, $\mathrm{BIO}$ would 
231 However, these positive effects do not equate to the same response mechanism of vegetation traits

232 to the AI in different grassland types on the northern Tibet Plateau. In contrast, earlier studies

233 revealed that grasslands with the different AI levels showed different response patterns to

234 vegetation biomass (Chen et al. 2016). Consistent with our research, in an alpine steppe (the AI

235 largely was less than 27.22), our experiments showed that $\mathrm{C}: \mathrm{N}$ and STN had positive effects while

236 SOC had negative effect on BIO (Fig. 6A). However, the opposite effects of soil on BIO were

237 detected in alpine meadow (the AI largely was greater than 43.79), as C: N and STN have negative

238 effects while SOC has positive effects on BIO (Fig. 6B). Generally, plant growth in alpine

239 grasslands was limited by soil N (Ladwig et al. 2012; Lambers et al. 2009). Illustrated by

240 comparing the nitrogen concentration of sub-humid and humid grasslands $(0.09 \%$ for the alpine

241 steppe and $0.18 \%$ for meadow, Table 1), STN increases with the increase in water supply (Fig. 6)

242 due to the rainfall and biological nitrogen fixation dominated by hydrothermal conditions (Aber et

243 al. 1998). However, when the water supply exceeds the needs of plant growth, the excessive water

244 content inhibits the decomposition of organic matter, and the STN increases further by the rainfall

245 and biological nitrogen fixation. This ecological process can be harmful to vegetation in bottom

246 land (Aber et al. 1998). However, these patterns do not apply to SOC because of its lower solubility

247 (Hyun et al. 1998). That is, why the mean value of SOC was largely the same (2.23\% for alpine

248 steppe and $2.37 \%$ for meadow) in two vegetation types despite gradual decline in soil organic

249 matter from increased the AI. This is because the increasing AI will intensify the activities of soil

250 microorganisms and soil animals and accelerate soil respiration, inevitably leading to the

251 acceleration of the release of $\mathrm{CO}_{2}$ from the soil carbon pool (Anderson 1992) and resulting in the 
252 imbalance between the input and output of soil carbon (Fig. 6). In this case, soil moisture was a

253 major limiting factor, and the drier climate of the alpine steppe produced a lack of water-soluble

254 organic carbon that was absorbed directly by the root and soil microorganisms, constraining the 255 development of root systems (Alexandre et al. 2016; Kick et al. 1964). In contrast, in the humid 256 environment of alpine meadow, the increase in water-soluble organic carbon in the soil led to 257 significant improvements in plant productivity (Atkinson et al. 2010). This indicated that the AI 258 (water and heat conditions) affected vegetation growth not only directly but also indirectly by modifying soil properties (i.e., soil moisture and soil nitrogen mineralization and availability) (Ruppert et al. 2012; Shaver et al. 2000; Wan et al. 2005).

\section{Conclusions}

In this study, we verified that the AI (integrated MAT and MAP) was the primary limiting environmental factor for vegetation traits in alpine grassland. Additionally, the different AI govern the different response patterns of BIO in the alpine steppe and the alpine meadow, respectively. The findings imply the important role of AI regulating vegetation dynamics, which need to be explored deeply in future research. Nevertheless, due to the unevenly distribution of the sampling sites throughout the vast region of northern Tibet plateau, the spatial heterogeneity of vegetation across regional environmental gradients limited this research. Hence, we should pay more attention to reduce spatial heterogeneity (i.e., optimize sampling methods or analytical methods) to verify the effect of AI on variations of biomass. 
273

274

275

276

277

278

279

280

281

282

283

284

285

286

287

288

289

290

291

292

293

294

295

296

297

298

299

300

301

302

303

304

305

306

307

\section{Acknowledgements}

The author thanks anonymous reviewers for providing invaluable comments on the original

manuscript. The author thanks the research team for the data collection of this study, Dr. Sun and

Dr. Zeng for their guidance of this paper, and his girlfriend (Ms. Zhang) for her support of his

work.

\section{References}

Aber J, Mcdowell W, Nadelhoffer K, Maqill A, Berntson G, Kamakea M, Mcnulty S, Currie W, and Rustad L. 1998. Nitrogen saturation in temperate forest ecosystem - hypothesis revisited. Bioscience 48:92-934.

Adler PB, and Levine JM. 2007. Contrasting relationships between precipitation and species richness in space and time. Oikos 116:221-232.

Alexandre A, Balesdent J, Cazevieille P, ChevassusRosset C, Signoret P, Mazur JC, Harutyunyan A, Doelsch E, BasileDoelsch I, and Miche H. 2016. Direct uptake of organic carbon by grass roots and allocation in leaves and phytoliths: 13C labeling evidence. Biogeosciences Discussions 12:19751-19780.

Anderson JM. 1992. Responses of Soils to Climate Change. Advances in Ecological Research 22:163-210.

Atkinson CJ, Fitzgerald JD, and Hipps NA. 2010. Potential mechanisms for achieving agricultural benefits from biochar application to temperate soils: a review. Plant \& Soil 337:1-18.

Cai Z, Huang B, and Lang B. 1989. Atlas of grassland and its main plants on qinghai-tibet plateau. Beijing: Agriculture Press.

Cantarel AAM, Bloor JMG, and Soussana JF. 2013. Four years of simulated climate change reduces above - ground productivity and alters functional diversity in a grassland ecosystem. Journal of Vegetation Science 24:113126.

Chen Y, Mu S, Sun Z, Gang C, Li J, Padarian J, Groisman P, Chen J, and Li S. 2016. Grassland carbon sequestration ability in china: A new perspective from terrestrial aridity zones. Rangeland Ecology and Management 69:84-94.

Chengjiang R, and Al E. 2002. Effect of soil moisture on survival rate of Hippophae rhamnoides $L$. and its stress resistance physiological characteristics. Chinese Journal of Applied \& Environmental Biology 8:341-345.

Chimner RA, Welker JM, Morgan J, Lecain D, and Reeder J. 2010. Experimental manipulations of winter snow and summer rain influence ecosystem carbon cycling in a mixed - grass prairie, Wyoming, USA. Ecohydrology 3:284-293.

Critchley CNR, Chambers BJ, Fowbert JA, Bhogal A, Rose SC, and Sanderson RA. 2010. Plant species richness, functional type and soil properties of grasslands and allied vegetation in English Environmentally Sensitive Areas. Grass \& Forage Science 57:82-92.

de Martonne E. 1926. L'indice d'aridité. Bulletin de l'Association de géographes français 3:3-5.

Epstein HE, Lauenroth WK, Burke IC, and Coffin DP. 1996. Ecological Responses of Dominant Grasses along Two Climatic Gradients in the Great Plains of the United States. Journal of Vegetation Science 7:777-788.

Peer) reviewing PDF | (2019:03:36005:2:0:NEW 4 Jun 2019) 
Fan Y, Chen JQ, Shirkey G, John R, Wu SR, Park H, and Shao CL. 2016. Applications of structural equation modeling (SEM) in ecological studies: an updated review. Ecological Processes 5(1): 19.

Flexas J, and Medrano H. 2002. Drought-inhibition of photosynthesis in C-3 plants: Stomatal and non-stomatal limitations revisited. Annals of Botany 89:183-189.

Ganjurjav H, Gao Q, Gornish ES, Schwartz MW, Liang Y, Cao X, Zhang W, Zhang Y, Li W, and Wan Y. 2016. Differential response of alpine steppe and alpine meadow to climate warming in the central QinghaiTibetan Plateau. Agricultural \& Forest Meteorology 223:233-240.

Hijmans RJ, Cameron SE, Parra JL, Jones PG, and Jarvis A. 2005. Very high resolution interpolated climate surfaces for global land areas. International Journal of Climatology 25:1965-1978.

Hu Z, Yu G, Fan J, Zhong H, Wang S, and Li S. 2010. Precipitation-use efficiency along a 4500-km grassland transect. Global Ecology \& Biogeography 19:842-851.

Huxman TE, Smith MD, Fay PA, Knapp AK, Shaw MR, Loik ME, Smith SD, Tissue DT, Zak JC, and Weltzin JF. 2004. Convergence across biomes to a common rain-use efficiency. Nature 429:651-654.

Hyun H, Chang AC, Parker DR, and Page AL. 1998. Cadmium Solubility and Phytoavailability in Sludge-Treated Soil: Effects of Soil Organic Carbon. Journal of Environmental Quality 27:329-334.

Kick H, Sauerbeck D, and Führ F. 1964. The uptake of carbon dioxide by plant roots. Plant \& Soil 21:303-316.

Ladwig LM, Collins SL, Swann AL, Xia Y, Allen MF, and Allen EB. 2012. Above- and belowground responses to nitrogen addition in a Chihuahuan Desert grassland. Oecologia 169:177-185.

Lambers H, Mougel C, Jaillard B, and Hinsinger P. 2009. Plant-microbe-soil interactions in the rhizosphere: an evolutionary perspective. Plant \& Soil 321:83-115.

Li XL, Gao J, Brierley G, Qiao YM, Zhang J, and Yang YW. 2013. RANGELAND DEGRADATION ON THE QINGHAI - TIBET PLATEAU: IMPLICATIONS FOR REHABILITATION. Land Degradation \& Development $24: 72-80$.

Li Y, Li Q, Guo D, Liang S, and Wang Y. 2016. Ecological stoichiometry homeostasis of Leymus chinensis in degraded grassland in western Jilin Province, NE China. Ecological Engineering 90:387-391. 10.1016/j.ecoleng.2016.01.079

Liu MY, and Chen FY. 1990. Effects of Stomatal and Nonstomatal Factors on Wheat Photosynthesis under Water Stress. Plant Physiology Communications 22:477-486.

Noymeir I. 1973. Desert Ecosystems: Environment and Producers. Annual Review of Ecology \& Systematics 4:25-51. O'Connor TG, Haines LM, and Snyman HA. 2001. Influence of precipitation and species composition on phytomass of a semi-arid African grassland. Journal of Ecology 89:850-860.

Orwin KH, Buckland SM, Johnson D, Turner BL, Smart S, Oakley S, and Bardgett RD. 2010. Linkages of plant traits to soil properties and the functioning of temperate grassland. Journal of Ecology 98:1074-1083.

Paoletti E, Raddi P, and Scala SL. 1998. Relationships between transpiration, stomatla damage and leaf wettability in declining beech trees. Chemosphere 36:907-912.

Redmann R, Romo J, Pylypec B, and Driver E. 1993. Impacts of burning on primary productivity of Festuca and Stipa-Agropyron grasslands in central Saskatchewan. American Midland Naturalist 130:262-273.

Ruppert JC, Holm A, Miehe S, Muldavin E, Snyman HA, Wesche K, and Linstädter A. 2012. Meta - analysis of ANPP and rain - use efficiency confirms indicative value for degradation and supports non - linear response along precipitation gradients in drylands. Journal of Vegetation Science 23:1035-1050.

Sala OE, and Parton WJ. 1988. Primary Production of the Central Grassland Region of the United States. Ecology 
69:40-45.

Shaver GR, Chapin FS, Gurevitch J, Harte J, Henry GIP, Jonasson S, Melillo J, Pitelka L, Rustad L, and Canadell J. 2000. Global warming and terrestrial ecosystems: A conceptual framework for analysis. Bioscience 50:871882.

Shi Y, Wang Y, Ma Y, Ma W, Liang C, Flynn DFB, Schmid B, Fang J, and He JS. 2014. Field-based observations of regional-scale, temporal variation in net primary production in Tibetan alpine grasslands. Biogeosciences 11:16843-16878.

Sun G, Luo P, Wu N, Qiu PF, Gao YH, Chen H, and Shi FS. 2009. Stellera chamaejasme L. increases soil N availability, turnover rates and microbial biomass in an alpine meadow ecosystem on the eastern Tibetan Plateau of China. Soil Biology \& Biochemistry 41:86-91.

Sun J, Cheng GW, and Li WP. 2013a. Meta-analysis of relationships between environmental factors and aboveground biomass in the alpine grassland on the Tibetan Plateau. Biogeosciences 10:1707-1715. DOI 10.5194/bg-10-1707-2013

Sun J, Cheng GW, Li WP, Sha YK, and Yang YC. 2013b. On the Variation of NDVI with the Principal Climatic Elements in the Tibetan Plateau. Remote Sensing 5:1894-1911. Doi 10.3390/Rs5041894

Sun J, Liu B, You Y, Li W, Liu M, Shang H, and He J-S. 2019. Solar radiation regulates the leaf nitrogen and phosphorus stoichiometry across alpine meadows of the Tibetan Plateau. Agricultural and Forest Meteorology 271:92-101.

Sun J, Ma B, and Lu X. 2017. Grazing enhances soil nutrient effects: Trade-offs between aboveground and belowground biomass in alpine grasslands of the Tibetan Plateau. Land Degradation \& Development. $10.1002 / \mathrm{ldr} .2822$

Sun J, and Qin X. 2016. Precipitation and temperature regulate the seasonal changes of NDVI across the Tibetan Plateau. Environmental Earth Sciences 75:1-9.

Sun J, Qin X, and Yang J. 2016. The response of vegetation dynamics of the different alpine grassland types to temperature and precipitation on the Tibetan Plateau. Environmental Monitoring \& Assessment 188:1-11.

Tang W, Zhou T, Sun J, Li Y, and Li W. 2017. Accelerated Urban Expansion in Lhasa City and the Implications for Sustainable Development in a Plateau City. Sustainability 9:1499.

Team RDC. 2016. R : A language and environment for statistical computing. R Foundation for Statistical Computing, Vienna, Austria. Computing 14:12-21.

Thomey ML, Collins SL, Vargas R, Johnson JE, Brown RF, Natvig DO, and Friggens MT. 2015. Effect of precipitation variability on net primary production and soil respiration in a Chihuahuan Desert grassland. Global Change Biology 17:1505-1515.

Wan S, Hui D, Wallace L, and Luo Y. 2005. Direct and indirect effects of experimental warming on ecosystem carbon processes in a tallgrass prairie. Global Biogeochemical Cycles 19:(2).

Wang Z, Li Y, Hao X, Zhao M, and Han G. 2015. Responses of plant community coverage to simulated warming and nitrogen addition in a desert steppe in Northern China. Ecological Research 30:1-10.

White SR, Bork EW, and Cahill JF. 2014. Direct and indirect drivers of plant diversity responses to climate and clipping across northern temperate grassland. Ecology 95:3093-3103.

Whittaker RH. 1972. Evolution and Measurement of Species Diversity. Taxon 21:213-251.

Wu J, Hong J, Wang X, Sun J, Lu X, Fan J, and Cai Y. 2013. Biomass Partitioning and Its Relationship with the Environmental Factors at the Alpine Steppe in Northern Tibet. Plos One 8:e81986. 
390

391

392

393

394

395

396

397

398

399

400

401

402
Yang YH, Fang JY, Pan YD, and Ji CJ. 2009. Aboveground biomass in Tibetan grasslands. Journal of Arid Environments 73:91-95.

Yu C, Zhang Y, Claus H, Zeng R, Zhang X, and Wang J. 2012. Ecological and environmental issues faced by a developing Tibet. Environmental Science \& Technology 46:1979.

Zeng C, Wu J, and Zhang X. 2015. Effects of grazing on above-vs. below-ground biomass allocation of alpine grasslands on the Northern Tibetan Plateau. Plos One 10:e0135173.

Zeng J, Shen J-P, Wang J-T, Hu H-W, Zhang C-J, Bai R, Zhang L-M, and He J-Z. 2018. Impacts of Projected Climate Warming and Wetting on Soil Microbial Communities in Alpine Grassland Ecosystems of the Tibetan Plateau. Microbial Ecology 75:1009-1023.

Zhang J, Sun J, Ma B, and Du W. 2017. Assessing the ecological vulnerability of the upper reaches of the Minjiang River. PLoS One 12:e0181825. 10.1371/journal.pone.0181825

Zhang R, Zheng Y, Guosheng MA, Zhang X, Haidong LU, and Shi J. 2011. Effects of drought stress on photosynthetic traits and protective enzyme activity in maize seeding. Acta Ecologica Sinica 31:1303-1311. 


\section{Table $\mathbf{1}$ (on next page)}

Description of the alpine grassland sampled sites across northern Tibet Plateau

Note: Al, SOC, C: N, STN, SR, BIO, and COV represent aridity index, soil organic carbon, the soil carbon to nitrogen ratio, soil total nitrogen, species richness, aboveground biomass, and coverage, respectively. 


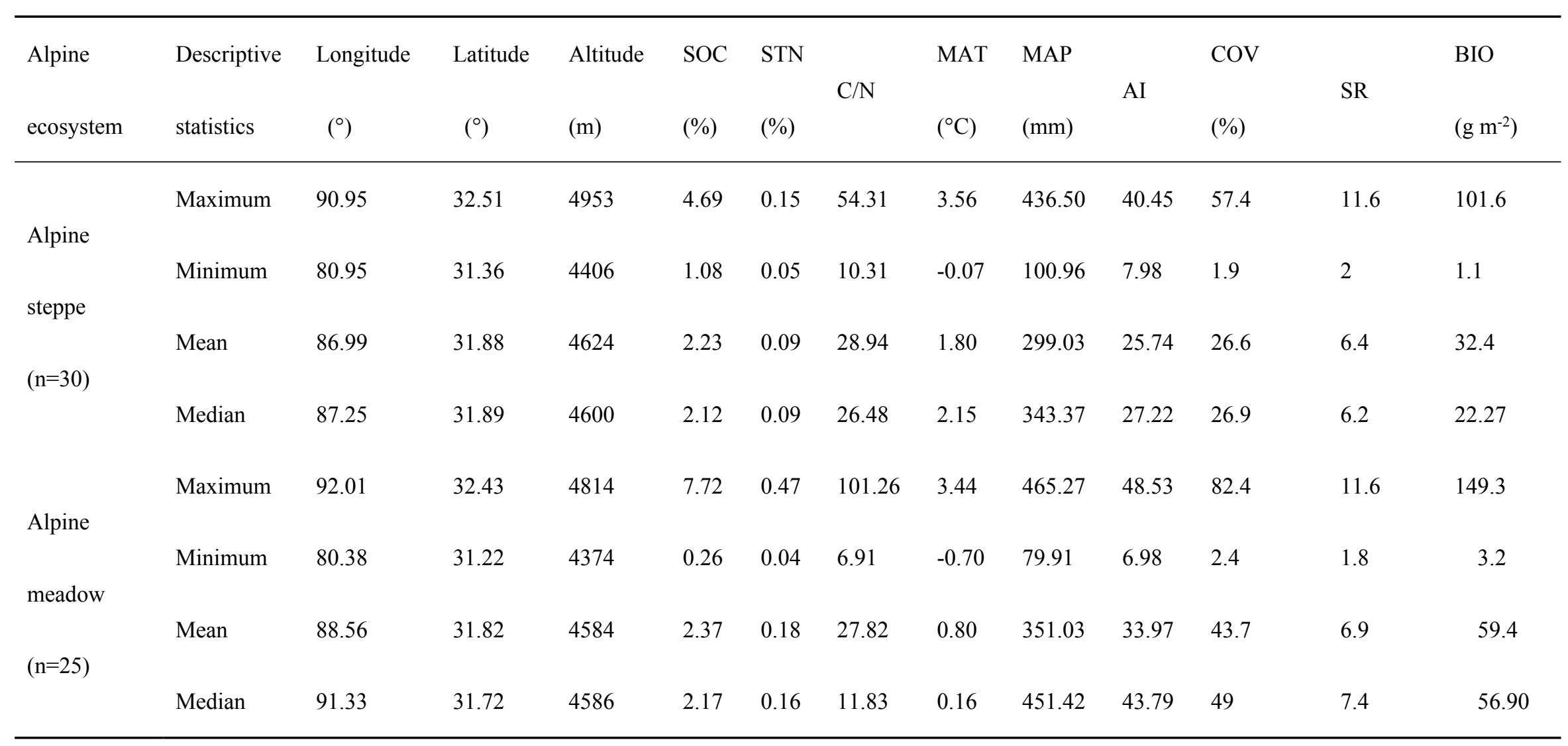




\section{Table 2 (on next page)}

Summary of the direct, indirect and total effects of variables (AI, STN, SOC, C: N, COV, $\mathrm{SR}, \mathrm{BIO})$ in the SEM of alpine steppe and alpine meadow. Effects were calculated with standardized path coefficients.

Note: Al, SOC, C: N, STN, SR, BIO, and COV represent aridity index, soil organic carbon, the soil carbon to nitrogen ratio, soil total nitrogen, species richness, aboveground biomass, and coverage, respectively. *** Correlation is significant at the 0.001 level. ** Correlation is significant at the 0.01 level. * Correlation is significant at the 0.05 level. 


\begin{tabular}{|c|c|c|c|c|c|c|c|c|c|c|c|c|c|}
\hline & & $\mathbf{A}$ & Direct & & & & & & B & Direct & fect & & \\
\hline Variable & AI & SOC & STN & C:N & $\mathrm{COV}$ & SR & Variable & AI & STN & SOC & C:N & $\operatorname{cov}$ & SR \\
\hline SOC & $-.463 *$ & .000 & .000 & .000 & .000 & .000 & STN & $.449 *$ & .000 & .000 & .000 & .000 & .000 \\
\hline STN & $.423 * *$ & .000 & .000 & .000 & .000 & .000 & SOC & -.247 & .000 & .000 & .000 & .000 & .000 \\
\hline C:N & $.140^{*}$ & $.776^{* * *}$ & $-.527 * * *$ & .000 & .000 & .000 & C:N & $-.471 * *$ & .228 & $.520^{* * *}$ & .000 & .000 & .000 \\
\hline $\mathrm{COV}$ & $.609 * * *$ & -.444 & .170 & .173 & .000 & .000 & COV & $.733^{* * *}$ & -.058 & $.371 * * *$ & $-.452 * * *$ & .000 & .000 \\
\hline SR & $.814^{* * *}$ & -.092 & -.043 & .000 & .000 & .000 & SR & $.842^{* * *}$ & .086 & .108 & -.074 & .000 & .000 \\
\hline BIO & .109 & $-.358 *$ & $.469 * *$ & .270 & $.357 * *$ & .179 & BIO & .105 & $-.047^{*}$ & $-.023 *$ & .041 & $.731 * * *$ & .182 \\
\hline & & C & Indirec & fect & & & & & D & Indirec & ffect & & \\
\hline Variable & AI & SOC & STN & C:N & $\mathrm{COV}$ & SR & Variable & AI & STN & SOC & C:N & $\mathrm{cov}$ & SR \\
\hline SOC & .000 & .000 & .000 & .000 & .000 & .000 & STN & .000 & .000 & .000 & .000 & .000 & .000 \\
\hline STN & .000 & .000 & .000 & .000 & .000 & .000 & SOC & .000 & .000 & .000 & .000 & .000 & .000 \\
\hline C:N & -.582 & .000 & .000 & .000 & .000 & .000 & C:N & -.026 & .000 & .000 & .000 & .000 & .000 \\
\hline $\mathrm{COV}$ & .200 & .134 & -.091 & .000 & .000 & .000 & COV & .107 & -.103 & -.235 & .000 & .000 & .000 \\
\hline SR & .024 & .000 & .000 & .000 & .000 & .000 & SR & .048 & -.017 & -.038 & .000 & .000 & .000 \\
\hline BIO & .684 & .083 & -.122 & .062 & .000 & .000 & BIO & .740 & -.096 & .134 & -.344 & .000 & .000 \\
\hline & & $\mathbf{E}$ & Total & & & & & & F & Total 1 & & & \\
\hline Variable & AI & SOC & STN & C:N & $\mathrm{COV}$ & SR & Variable & AI & STN & SOC & C:N & $\operatorname{cov}$ & SR \\
\hline SOC & -.463 & .000 & .000 & .000 & .000 & .000 & STN & .449 & .000 & .000 & .000 & .000 & .000 \\
\hline STN & .423 & .000 & .000 & .000 & .000 & .000 & SOC & -.247 & .000 & .000 & .000 & .000 & .000 \\
\hline C:N & -.442 & .776 & -.527 & .000 & .000 & .000 & C:N & -.497 & .228 & .520 & .000 & .000 & .000 \\
\hline $\mathrm{COV}$ & .809 & -.309 & .078 & .173 & .000 & .000 & $\operatorname{cov}$ & .840 & -.161 & .136 & -.452 & .000 & .000 \\
\hline SR & .838 & -.091 & -.044 & .000 & .000 & .000 & SR & .891 & .069 & .069 & -.074 & .000 & .000 \\
\hline BIO & .793 & -.276 & .347 & .331 & .357 & .179 & BIO & .844 & -.143 & .111 & -.303 & .731 & .182 \\
\hline
\end{tabular}

1 
Figure 1

The distribution of sampled sites in alpine grasslands across northern Tibet Plateau.

The yellow solid triangles represent the samples collected in alpine meadow while the black solid triangles represent the samples collected in alpine steppe. In addition, the gray areas and the olive areas represent alpine meadow and steppe, respectively.

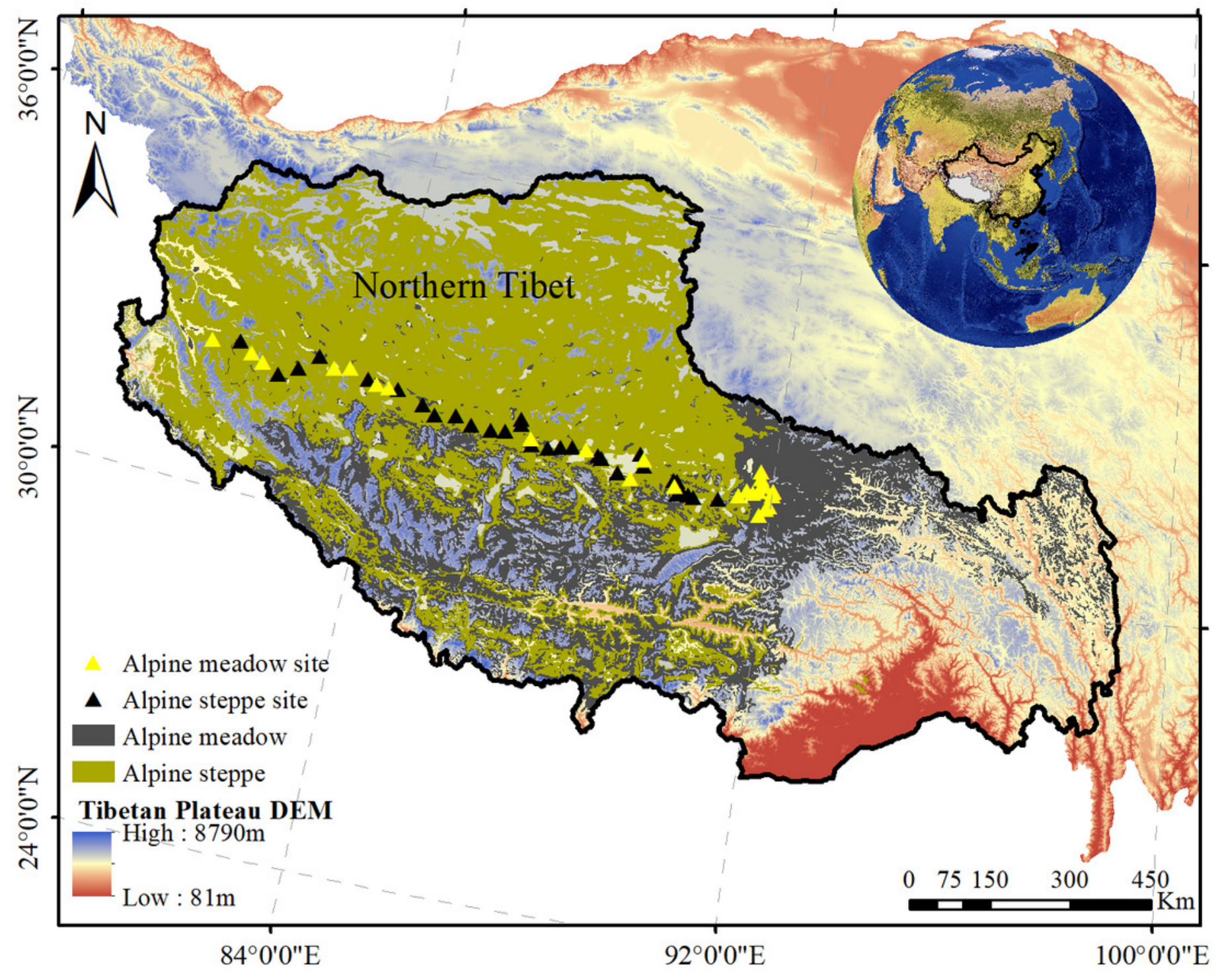




\section{Figure 2}

The correlationships of aboveground biomass with environmental factors.

The colored solid circles represent the significant correlation ( $p \square 0.05)$. And the MAT, MAP, Al, SOC, C: N, STN and BIO represent mean annual temperature, mean annual precipitation, aridity index, soil organic carbon, the soil carbon to nitrogen ratio, soil total nitrogen and aboveground biomass, respectively. 


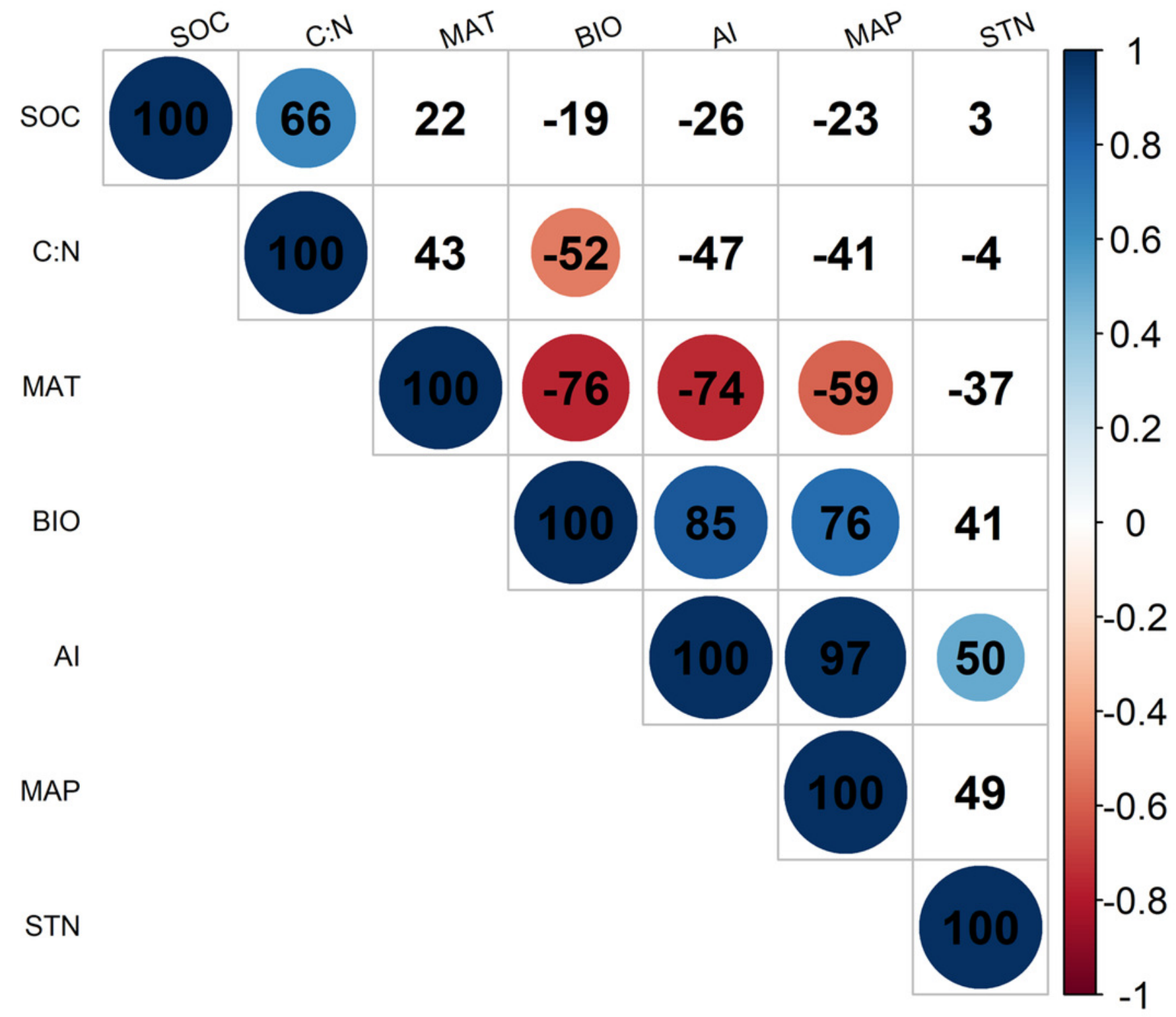


Figure 3

The contributions (\%) of the different critical environmental variables to aboveground biomass via redundancy analysis.

The MAT, C: N, MAP and Al represent mean annual temperature, the soil ratio of carbon to nitrogen, mean annual precipitation and the aridity index, respectively. 


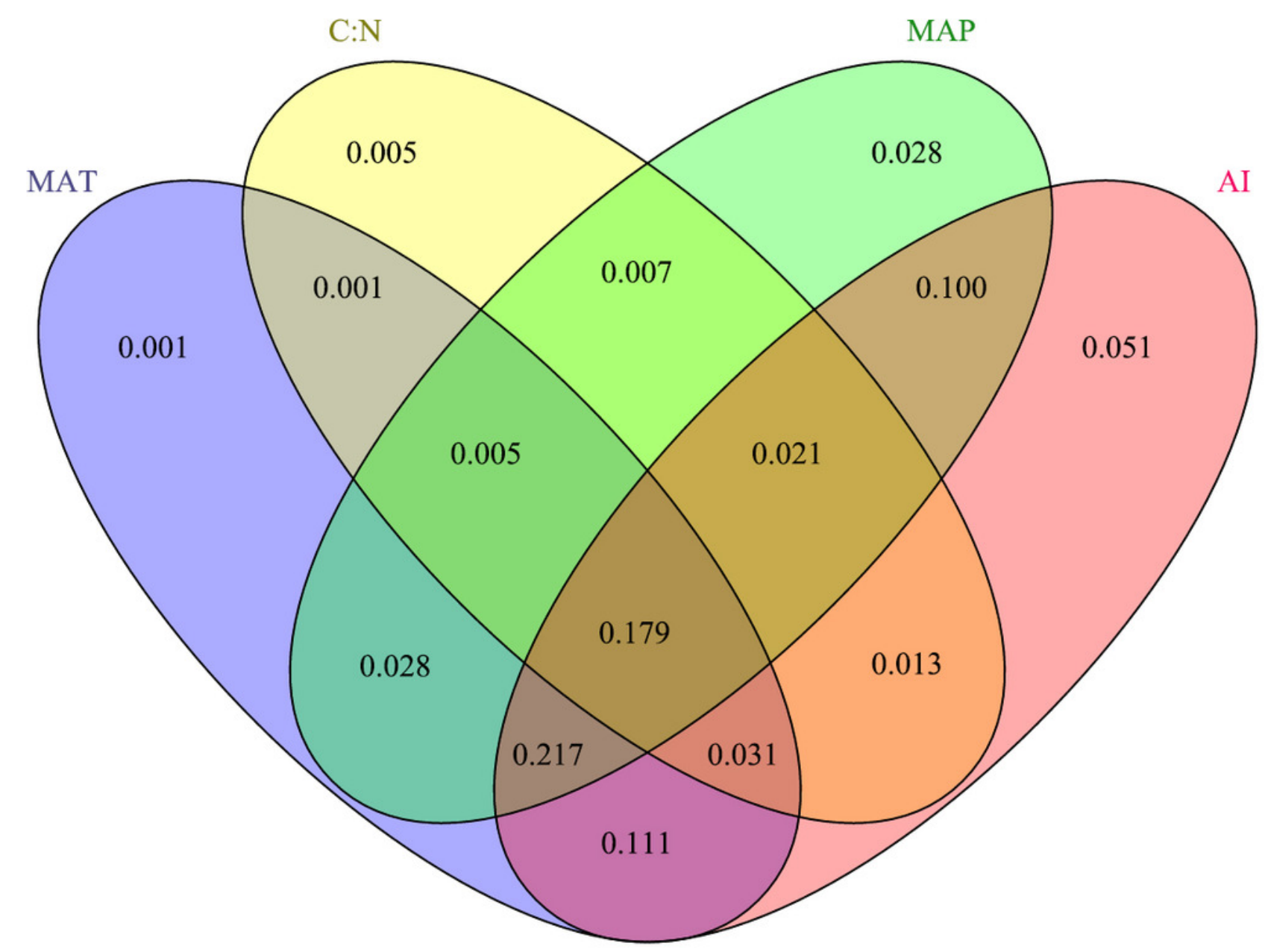


Figure 4

The variances of $\mathrm{Al}(\mathrm{A})$ and aboveground biomass (B) in alpine steppe and meadow, respectively.

** and * represent the significance at the 0.01 and 0.05 level.

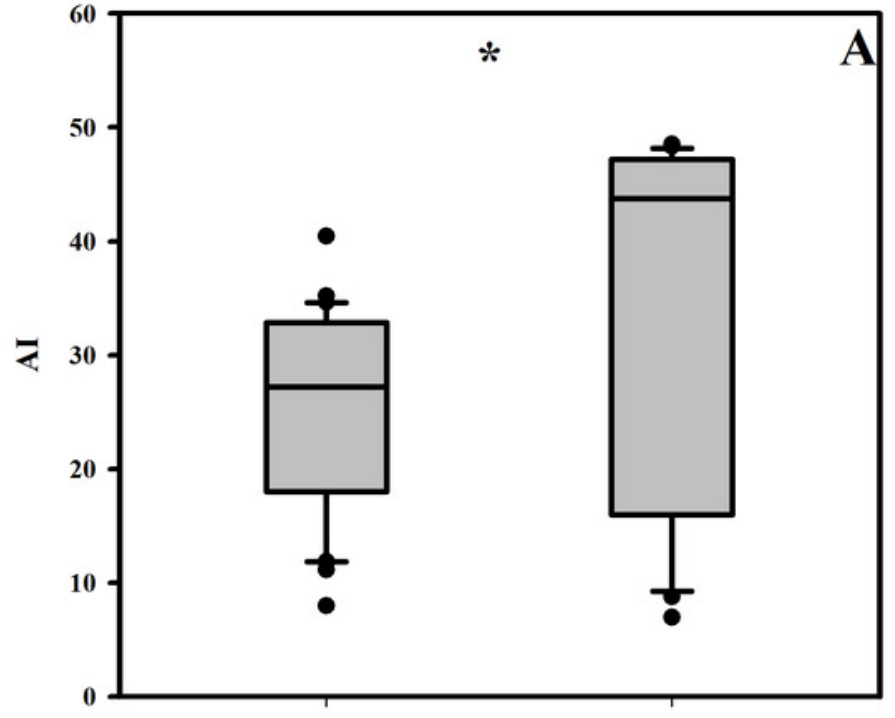

Alpine steppe

Alpine meadow

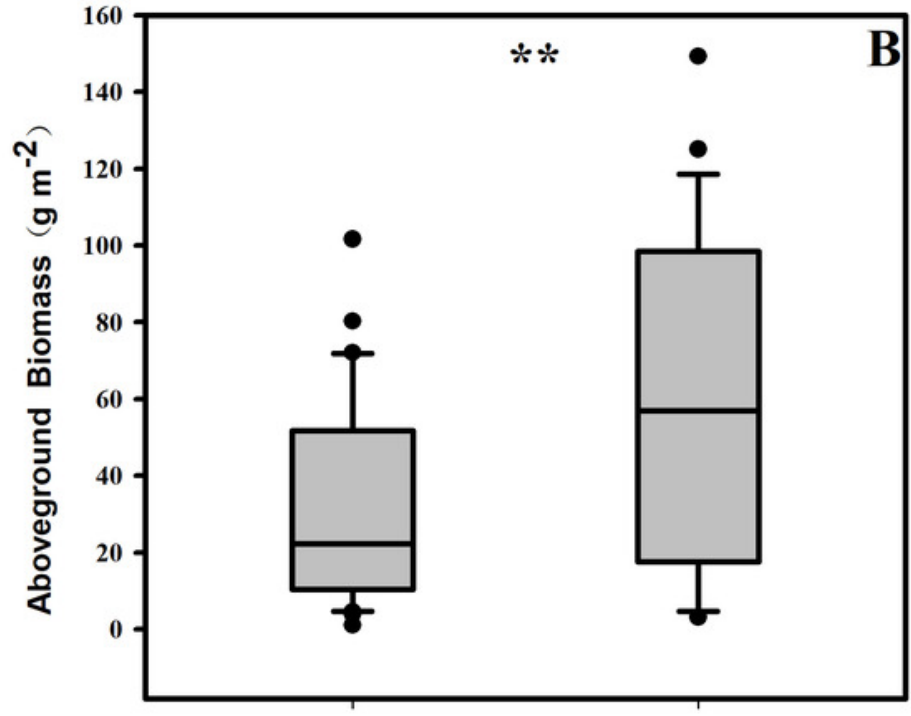

Alpine steppe
Alpine meadow 


\section{Figure 5}

Relationships between aboveground biomass and the aridity index (Al).

The black solid circle and hollow circle represent the samples collected in alpine steppe and alpine meadow respectively. The solid lines represent the fitting curves of alpine steppe, and the dotted lines represent the fitting curves of alpine meadow. 


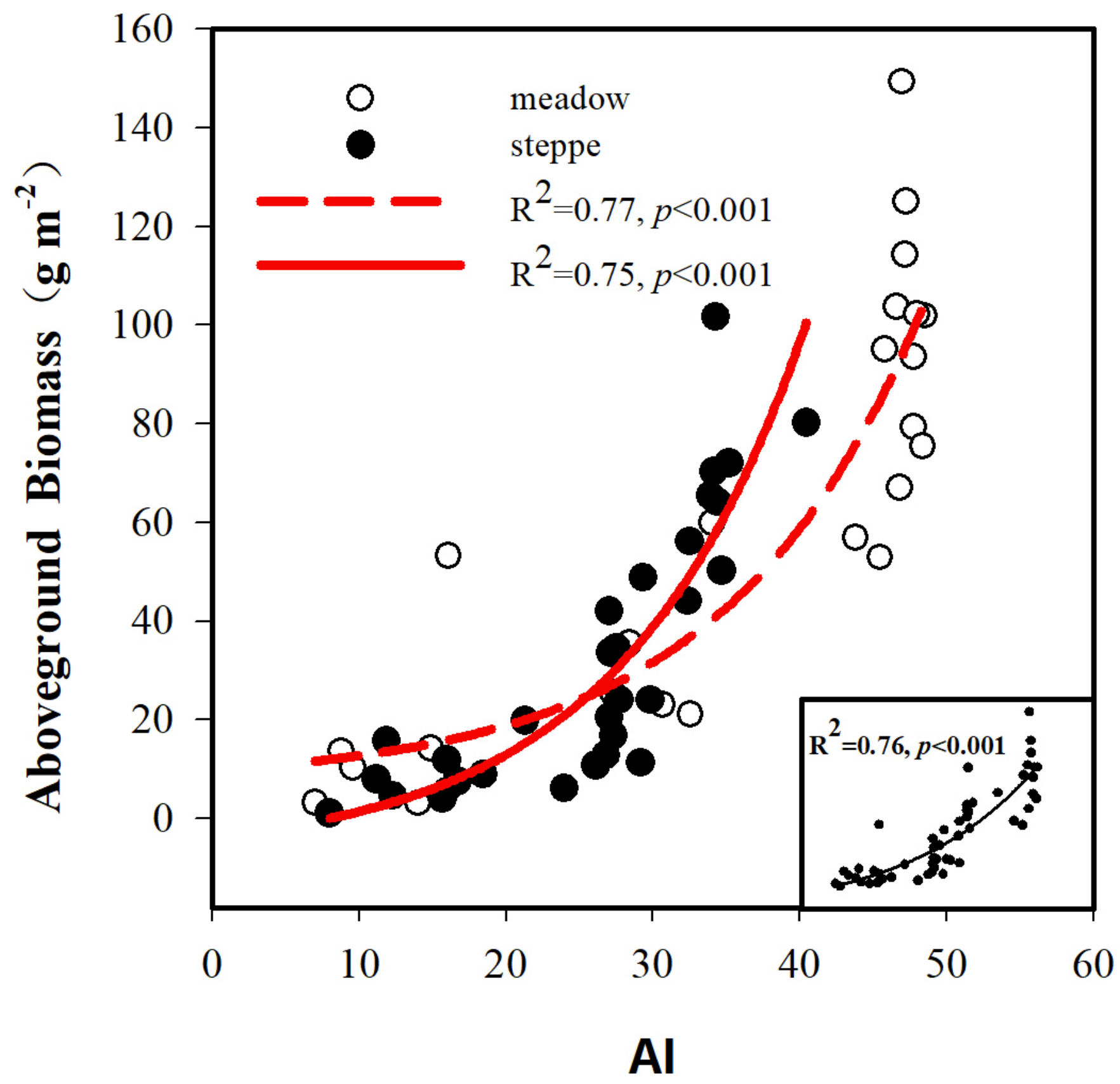


Figure 6

Using the SEM to analyze the directly and indirectly effects among variables in alpine steppe (Graph A) and alpine meadow (Graph B), respectively.

The standardized total coefficients are listed on each significant path. The thickness of the solid arrows reflects the magnitude of the standardized SEM coefficients, the black solid line represents the positive effect while the red solid line represents the negative effect. The Al, SOC, C: N, STN, SR, BIO, COV represent aridity index, soil organic carbon, the soil carbon to nitrogen ratio, soil total nitrogen, species richness, aboveground biomass, coverage, respectively.
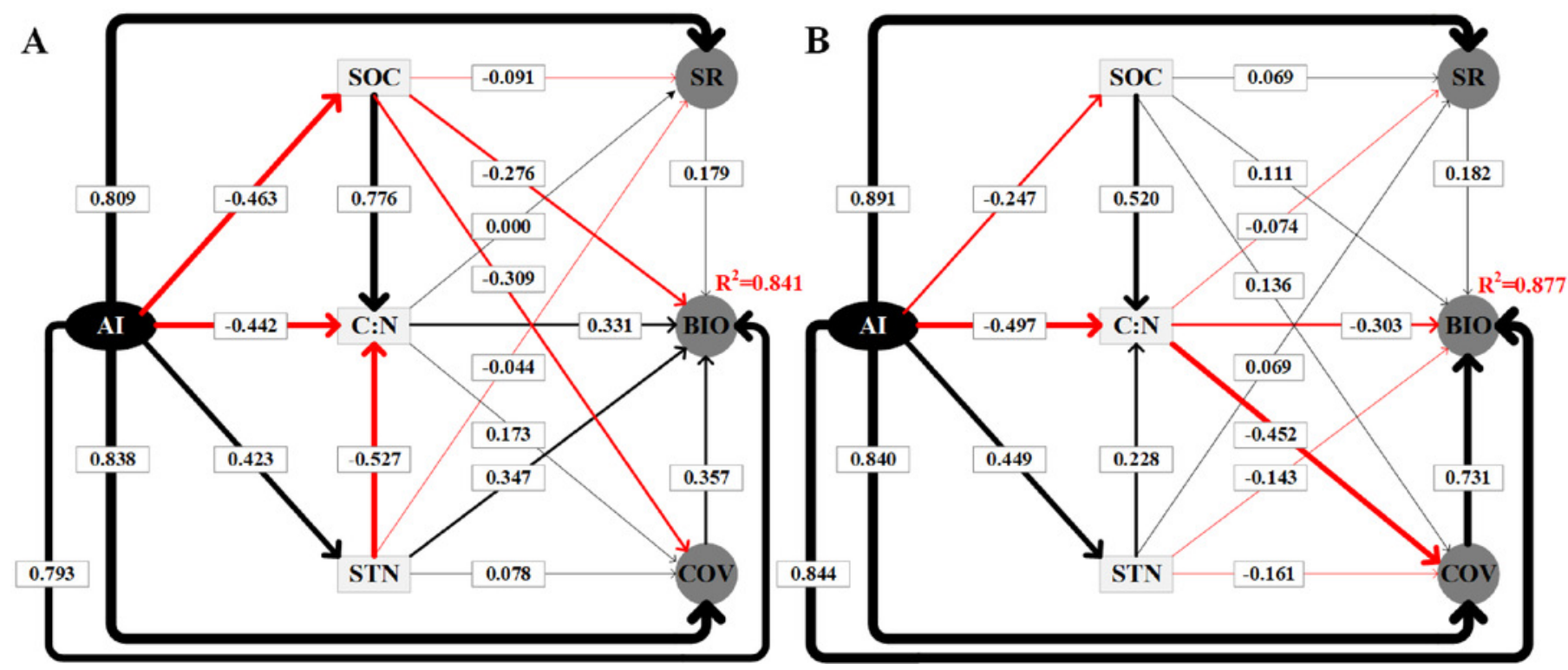